\title{
Improved iron gettering of contaminated multicrystalline silicon by high-temperature phosphorus diffusion
}

\author{
D. P. Fenning, ${ }^{1, a), b)}$ A. S. Zuschlag, ${ }^{2, a)}$ M. I. Bertoni, ${ }^{1, c)}$ B. Lai, ${ }^{3}$ G. Hahn, ${ }^{2}$ \\ and T. Buonassisi ${ }^{1, b)}$ \\ ${ }^{1}$ Massachusetts Institute of Technology, Cambridge, Massachusetts 02139, USA \\ ${ }^{2}$ University of Konstanz, Department of Physics, P.O. Box X916, 78457 Konstanz, Germany \\ ${ }^{3}$ Advanced Photon Source, Argonne National Laboratory, Argonne, Illinois 60439, USA
}

(Received 9 March 2013; accepted 15 May 2013; published online 4 June 2013)

\begin{abstract}
The efficacy of higher-temperature gettering processes in reducing precipitated iron concentrations is assessed by synchrotron-based micro-X-ray fluorescence. By measuring the same grain boundary before and after phosphorus diffusion in a set of wafers from adjacent ingot heights, the reduction in size of individual precipitates is measured as a function of gettering temperature in samples from the top of an ingot intentionally contaminated with iron in the melt. Compared to a baseline $820^{\circ} \mathrm{C}$ phosphorus diffusion, $870^{\circ} \mathrm{C}$ and $920^{\circ} \mathrm{C}$ diffusions result in a larger reduction in iron-silicide precipitate size. Minority carrier lifetimes measured on wafers from the same ingot heights processed with the same treatments show that the greater reduction in precipitated metals is associated with a strong increase in lifetime. In a sample contaminated with both copper and iron in the melt, significant iron gettering and complete dissolution of detectable copper precipitates is observed despite the higher total metal concentration. Finally, a homogenization pre-anneal in $\mathrm{N}_{2}$ at $920^{\circ} \mathrm{C}$ followed by an $820^{\circ} \mathrm{C}$ phosphorus diffusion produces precipitate size reductions and lifetimes similar to an $870^{\circ} \mathrm{C}$ phosphorus diffusion without lowering the emitter sheet resistance. (C) 2013 AIP Publishing LLC. [http://dx.doi.org/10.1063/1.4808310]
\end{abstract}

\section{INTRODUCTION}

In a traditional silicon solar cell process, the majority of the high-purity silicon feedstock starting material is discarded after crystal growth: during cropping to remove highly contaminated regions and during wafering due to kerf loss. This loss of cost- and energy-intensive silicon adds significantly to the subsequent cost of solar power. ${ }^{1,2}$ At the same time, there is a strong push in the industry to higher efficiencies, making a significant fraction of cells produced today that end up in the bottom tail of the distribution unacceptable because of high impurity concentrations. ${ }^{3}$ One path to achieve tighter solar cell efficiency distributions with higher average values, while also achieving better silicon utilization, is to recover high carrier lifetimes in previously unusable wafers or wafers that would otherwise turn into unsalable cells.

To quantify the metal impurity problem, several benchmark studies have updated the specifications of tolerance limits of metal impurities in a standard silicon solar cell process. ${ }^{4,5}$ The defect concentration limits extracted (e.g., 2-5 ppma Fe in the feedstock) are similar to the landmark Westinghouse study of impurities in silicon solar cells, ${ }^{6}$ in large part because even as solar cell processing and architectures have advanced, so have efficiency targets. The end result is the same despite improved processing: even in ingots cast using electronic-grade silicon, solar cells from the tops of ingots have unacceptably low efficiencies due in

\footnotetext{
a) The first two authors contributed equally to this work.

${ }^{\text {b) }}$ Electronic addresses: dfenning@alum.mit.edu and buonassisi@mit.edu.

${ }^{c}$ Currently at Department of Electrical, Computer and Energy Engineering, Arizona State University, Tempe, AZ.
}

part to high metal concentrations that exceed the specified limits. ${ }^{4,5}$ In addition to the tops of ingots, wafers from the "red zone" near the crucible wall typically exceed "allowable" impurity specifications. ${ }^{7}$

Novel processing schemes are needed to achieve high efficiencies in such wafers. One recently developed technique, low-temperature annealing (LTA), has been shown by a number of authors to reduce metal point defect concentrations, particularly iron, and improve lifetime in border region materials. ${ }^{8-12}$ However, lifetimes after LTA often remain too low to meet today's efficiency requirements. LTA has limited effectiveness in part because precipitated metals remain inside the bulk. ${ }^{13}$ In the bulk, precipitates can affect lifetime directly due to recombination at their surfaces ${ }^{14,15}$ or can redissolve during metallization firing, poisoning the bulk. ${ }^{16-18}$

An alternative path to reduce the impact of metal impurities is to use higher-temperature processes. ${ }^{19}$ By increasing bulk solubility and speeding diffusion to near-surface gettering layers, higher-temperature diffusions are expected to improve the extraction of metals from the bulk, including deleterious iron. To date, experiments seeking lifetime improvements via high-temperature diffusions have seen mixed results. For example, Peters et al., ${ }^{20}$ Ballif et al., ${ }^{21}$ and Macdonald et al. ${ }^{22}$ observed lifetime degradation after higher-temperature diffusions in a variety of silicon materials. In contrast, recent investigations by Osinniy et al. ${ }^{23}$ showed lifetime improvement in solar-grade silicon after variable-temperature diffusion like the temperature profile recommended by Plekhanov et al., ${ }^{19}$ supporting the hypothesis of improved impurity gettering indirectly through lifetime measurements. Similarly, Schön et al. ${ }^{24}$ used a hightemperature pre-annealing in $\mathrm{N}_{2}$ before phosphorus diffusion 
to improve lifetime. On the other hand, without showing lifetime improvement, Macdonald et al. ${ }^{25}$ recently used micro$\mathrm{X}$-ray fluorescence $(\mu$-XRF) measurements to determine that the percentage of surface area covered by iron-rich precipitates was lower after higher-temperature processing in wafers originating from the bottom of a cast ingot. While millimeter-sized areas were sampled, the collection of grain boundaries investigated in each sample differed as samples from adjacent ingot heights, i.e., with the same grain structure, were not used.

In this contribution, we show direct evidence from synchrotron-based $\mu$-XRF measurements that the precipitated iron concentration decreases significantly after highertemperature phosphorus diffusion, using measurements of the same precipitates before and after phosphorus diffusion to draw conclusions. We then directly relate this decrease in precipitated metals to a marked improvement in bulk carrier lifetime in multicrystalline silicon contaminated with iron.

\section{MATERIALS AND METHODS}

To determine the impact of gettering process conditions on metal precipitate distribution, we use $\mu$-XRF measurements to characterize the metal distribution along the same $\sim 20 \mu \mathrm{m}$ length of a selected grain boundary (GB) before and after phosphorus diffusion gettering (PDG) in a set of sister samples (samples from adjacent ingot heights). The phosphorus diffusion temperature profile was varied for each sister to investigate the effect of the gettering temperature.

\section{A. Wafer and region of interest selection}

Full $15.6 \times 15.6 \mathrm{~cm}^{2}$ wafers were selected from approximately $92 \%$ ( $\sim 177 \mathrm{~mm}$ ) ingot height from two ingots grown as part of the German SolarFocus project: one intentionally contaminated in the melt with 20 ppma Fe, and the other with 20 ppma $\mathrm{Fe}$ and 20 ppma $\mathrm{Cu}$. Neutron activation analysis of the total impurity concentrations within these ingots as a function of ingot height can be found in Riepe et al. ${ }^{4}$ From this data, the Fe concentration in these wafers is estimated to be on the order of $10^{15}$ atoms $/ \mathrm{cm}^{3}$. In the $\mathrm{Fe}+\mathrm{Cu}$ contaminated samples, the $\mathrm{Cu}$ concentration should be on the order of $\sim 5 \times 10^{16}$ atoms $/ \mathrm{cm}^{3}$, while the unintentional $\mathrm{Cu}$ concentration in the intentionally only $\mathrm{Fe}$-contaminated samples should be $\sim 3 \times 10^{14}$ atoms $/ \mathrm{cm}^{3}$. To focus on the impact of the intentional metal contamination and avoid the influence from impurity in-diffusion from the crucible wall, a stack of $5 \times 5 \mathrm{~cm}^{2}$ sister samples were cut from the full wafers from the region close to the center of the laboratory-scale ingot.

Electron-beam induced current and electron backscatter diffraction (not shown) were measured on one sister sample to select a recombination-active, random-angle GB for $\mu$-XRF investigation. This same GB was investigated in all samples except the sample that underwent a $920^{\circ} \mathrm{C} \mathrm{POCl}_{3}$ diffusion. In that sample, we investigated a second comparable, recombination-active, random-angle GB that was $2.5 \mathrm{~cm}$ from the GB of the other samples because no additional sister samples were available. Before as-grown (AG) $\mu$-XRF measurement, the samples were etched with an acidic saw-damage etch followed by a cleaning sequence of hydrochloric acid $(\mathrm{HCl})$ and hydrofluoric acid (HF).

\section{B. Synchrotron-based $\mu$-XRF measurement details}

The $\mu$-XRF measurements were conducted at Beamline 2-ID-D at the Advanced Photon Source at Argonne National Laboratory. ${ }^{26}$ A $200 \mathrm{~nm}$ full-width half-maximum, $10 \mathrm{keV}$ beam was used to map the sample using $220 \mathrm{~nm}$ steps, with a $1 \mathrm{~s}$ dwell time per pixel. NIST standard reference materials 1832 and 1833 were used to convert fluorescence counts into area concentrations.

To reveal the impact of the gettering step on the metal precipitate distribution, different phosphorus diffusions were conducted on the sister samples following synchrotron measurement of the as-grown metal distribution.

Three diffusions on the Fe-contaminated synchrotron samples used an extended drive-in step and varied in peak temperature only: at 820,870 , and $920^{\circ} \mathrm{C}$. Total plateau time at process temperature was $76 \mathrm{~min}$. The fourth $\mathrm{Fe}$-contaminated synchrotron sample was first annealed in $\mathrm{N}_{2}$ at $920^{\circ} \mathrm{C}$ before the temperature was lowered to $820^{\circ} \mathrm{C}$ for phosphorus diffusion and a standard drive-in (54 min total plateau time), inspired by lifetime improvements shown previously using pre-annealing. ${ }^{18,24}$ Additionally, one $\mathrm{Fe}+\mathrm{Cu}$-contaminated sample was investigated at the synchrotron. It was processed using the $870^{\circ} \mathrm{C}$ phosphorus diffusion with extended drive-in, which gave the highest lifetimes after the extended gettering. All samples were pulled from the diffusion furnace at $820^{\circ} \mathrm{C}$, and the cooling rate to $820^{\circ} \mathrm{C}$ for the higher-temperature processes was $\sim 6^{\circ} \mathrm{C} / \mathrm{min}$. The four different phosphorus diffusion time-temperature profiles used are shown schematically in Figure 1.

Before high-temperature treatment, the synchrotron samples were cleaned again by a sequence of $\mathrm{HCl}$ and $\mathrm{HF}$. Following the phosphorus diffusion, the phosphorus glass was removed from the surface of the sample by dipping in $\mathrm{HF}$, but the phosphorus-diffused emitter was left on the sample to compare precipitates near to the surface that were observed in the as-grown $\mu$-XRF measurements. The resulting sheet resistance of each process was measured on an additional boron-doped p-type Czochralski $(\mathrm{Cz})$ monocrystalline wafer (1-3 $\Omega$-cm resistivity) included in the diffusion for that purpose.

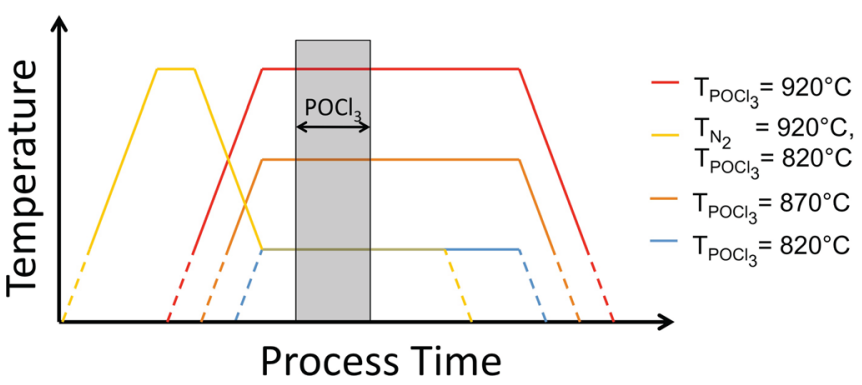

FIG. 1. The time-temperature profiles of the phosphorus diffusion processing used in this study are shown. Three different peak temperatures were used: 820,870 , and $920^{\circ} \mathrm{C}$. In addition, one sample was included that had a pre-anneal at $920^{\circ} \mathrm{C}$, but the phosphorus diffusion was carried out at $820^{\circ} \mathrm{C}$. 
The samples were returned to the synchrotron to remeasure the metal distributions after phosphorus diffusion using identical experimental conditions to the as-grown measurements. Test samples produced by e-beam lithography containing metallic copper dots down to $8 \mathrm{~nm}$ in radius ${ }^{27}$ were measured at the start of both synchrotron runs to verify that XRF sensitivity was indeed similar between runs.

\section{Carrier lifetime measurements}

Microwave photoconductance decay ( $\mu$-PCD) lifetime measurements were performed using a Semilab WT-2000 on a neighboring stack of $5 \times 5 \mathrm{~cm}^{2}$ sister samples (also unaffected by the crucible wall) to evaluate the impact of processing on high metal contamination levels.

Two sister wafers in the stack were measured as-grown. These as-grown lifetime samples were prepared using the same saw-damage etch and $\mathrm{HCl}$ and $\mathrm{HF}$ sequence as above. The remaining sisters in the stack, corresponding to the same heights as the synchrotron samples, were phosphorus diffused after saw-damage etch and $\mathrm{HCl}$ and $\mathrm{HF}$ cleaning according to the same profiles as described above (see Figure 1). These sister wafers, from lower ingot height to higher (centered around $92 \%$ ingot height), were assigned to the $820,870,920$, and $920^{\circ} \mathrm{C} / 820^{\circ} \mathrm{C}$ processes, respectively. Post-diffusion lifetime measurements were performed after etching back approximately $5-10 \mu \mathrm{m}$ per side to remove the emitter using a fresh damage etch solution, followed by the same $\mathrm{HCl}, \mathrm{HF}$ sequence before lifetime measurement.

All lifetime measurements reported here used a solution of iodine ethanol (I-E) to passivate the sample surfaces. To ensure comparability, all samples were additionally cleaned by piranha etch followed by an HF dip, and measured immediately following exposure to the I-E. ${ }^{28}$

\section{RESULTS}

\section{A. Fe-contaminated synchrotron samples}

The resulting iron concentration distribution maps from $\mu$-XRF measurement of the Fe contaminated samples are shown in Figure 2 according to the phosphorus-diffusion treatment that was applied to the sample. All maps in Figure 2 are shown on the same logarithmic iron concentration scale to allow for direct comparison. We did not observe a significant amount of other metals by $\mu$-XRF in the Fe-contaminated samples.

Precipitates - the highly localized, high-concentration agglomerations of iron in the $\mu$-XRF maps - are seen in high density both before and after phosphorus diffusion. Many of the larger precipitates (e.g., those numbered for the $920^{\circ} \mathrm{C}$ PDG sample) are readily identifiable as the same precipitate before and after phosphorus diffusion, indicating that even the highest temperature phosphorus diffusion here $\left(920^{\circ} \mathrm{C}\right)$ does not fully dissolve the largest precipitates. On the other hand, close inspection of the maps reveals that in each sample, a number of precipitates observed in the as-grown sample are not observed after phosphorus diffusion (e.g., those in bottom left and top left of $920^{\circ} \mathrm{C}$ PDG sample). The disappearance of some precipitates signifies their dissolution—at least to levels below the

\section{Fe Contaminated Ingot}

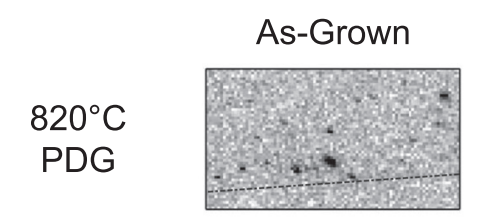
P-Diffused

\section{$870^{\circ} \mathrm{C}$ PDG}
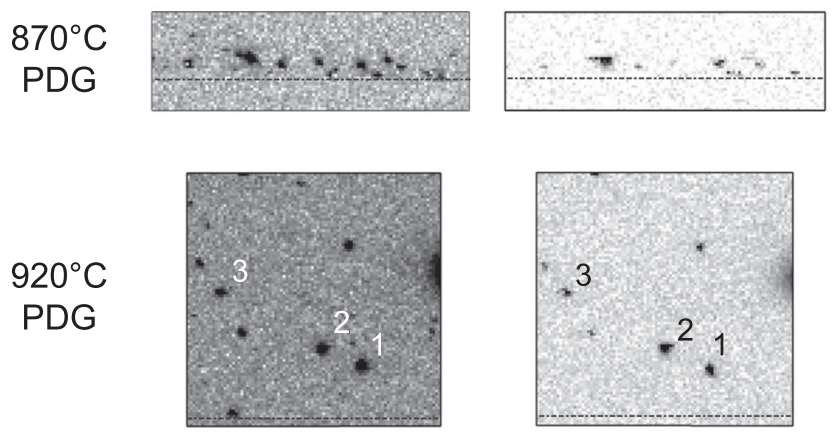
$920^{\circ} \mathrm{C} \mathrm{N}_{2}$ $+820^{\circ} \mathrm{C}$ PDG
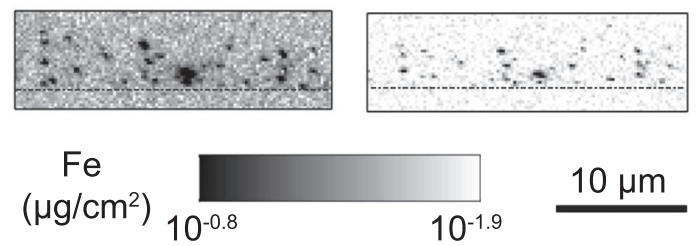

FIG. 2. Maps of iron concentrations $\left(\mu \mathrm{g} / \mathrm{cm}^{2}\right)$ in each sample AG and after PDG as measured by $\mu$-XRF. The same grain boundary was measured for the 820,870 , and $920^{\circ} \mathrm{C} \mathrm{N}_{2}+820^{\circ} \mathrm{C}$ PDG samples. A dashed line indicates the position of the grain boundary at the surface of the sample in each image.

detection limit of the measurement (estimated to be $5 \times 10^{4}$ atoms/precipitate). Thus, the extended, high-temperature phosphorus diffusion gettering steps appear to fully dissolve some precipitates while the largest remain.

Inspection of linescans of the as-grown maps (not shown) reveals that the background level increases in the regions immediately surrounding precipitates. In addition, the $920^{\circ} \mathrm{C}$ PDG sample has the largest as-grown precipitates and also the highest background level. While some contribution to the background is attributable to impurities in the detector and scattering off instruments in the beamline hutch, the relationship between the presence of large precipitates and a higher background level suggests the background is also indicative of the presence of high iron concentration in the sample. Thus, a decrease in background level after phosphorus diffusion indicates a decrease in iron concentration in the region measured. From the difference in the coloring of the background level between the as-grown maps and the phosphorus-diffused maps in Figure 2, it appears that in all cases the phosphorus diffusion step reduces the level of iron in these samples.

To further quantify the changes in distribution of ironrich precipitates in each sample, the size of each precipitate in Figure 2 was estimated using an automated routine to identify iron-rich precipitates from pixels containing iron concentrations more than three standard deviations above the average background level. An effective precipitate radius was calculated from the concentration maps assuming all iron atoms within high-Fe pixels could be attributed to a 


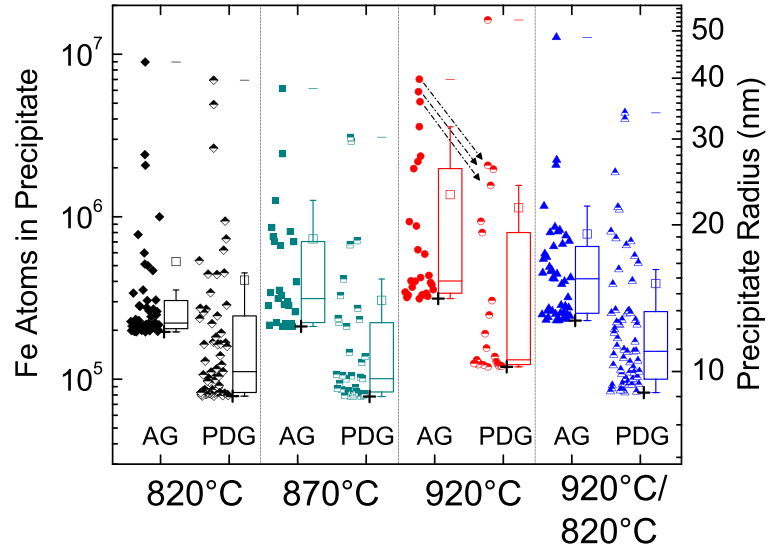

FIG. 3. Quantified precipitate size distributions for the Fe contaminated samples in the as-grown state and after gettering according to the diffusion process used for each sample. The boxplots to the right of each data set show the quartiles of the distribution, while the open squares show the mean precipitate size. The cross at the bottom of each distribution indicates the effective detection limit in each sample below which precipitates could not be separated from the background.

single spherical $\beta-\mathrm{FeSi}_{2}$ precipitate located at the surface of the sample. Similarly, for the $\mathrm{Fe}+\mathrm{Cu}$ contaminated sample, high- $\mathrm{Cu}$ pixels were attributed to $\mathrm{Cu}_{3} \mathrm{Si}$ precipitates. Further details on the $\mu$-XRF data analysis and the extraction of precipitate distributions can be found in Ref. 29.

The resulting precipitate size distributions are shown for each sample in the AG state and after PDG in Figure 3. In some cases, the PDG $\mu$-XRF map was larger with respect to the AG map in order to be sure to capture the same region of interest for the direct comparison above. In an effort to include all available data, in Figure 3, all measured precipitates are shown, including those from the PDG maps outside the region shown in Figure 2.

The shift toward smaller precipitate sizes after phosphorus diffusion is clear in Figure 3, where each point represents one precipitate. In each sample, all distribution parameters are smaller after phosphorus diffusion relative to the asgrown state, as revealed by comparison of the distribution boxplots to the right of the data.

It is important to note that the cross at the bottom of each distribution in Figure 2 represents the limit beyond which precipitates could not be distinguished from the background level of the map. Due to higher levels of iron measured in the as-grown samples, the background level is higher, perhaps excluding existing smaller precipitates from inclusion in the distribution parameter estimates. However, as mentioned above, many of the precipitates can be clearly, uniquely identified before and after diffusion such that small precipitates omitted from the as-grown distributions should be similarly excluded from the phosphorus-diffused distribution analysis.

In addition to the size distribution, the linear density of precipitates at each GB can be extracted from the $\mu$-XRF maps before and after gettering and is shown in Table I for all samples in this study. In addition to a reduction in precipitate sizes, the density of precipitates decreases in all cases after PDG.

Three particles in the $920^{\circ} \mathrm{C}$ sample, labeled 1,2 , and 3 in order from largest to smallest in Figure 2, are among the
TABLE I. Measured linear density of Fe precipitates along the GB of interest for each sample in the as-grown state and after phosphorus diffusion gettering.

\begin{tabular}{lccccc}
\hline \hline & $\begin{array}{c}\mathrm{Fe} 820{ }^{\circ} \mathrm{C} \\
\mathrm{POCl}_{3}\end{array}$ & $\begin{array}{c}\mathrm{Fe} 870{ }^{\circ} \mathrm{C} \\
\mathrm{POCl}_{3}\end{array}$ & $\begin{array}{c}\mathrm{Fe} 920{ }^{\circ} \mathrm{C} \\
\mathrm{POCl}_{3}\end{array}$ & $\begin{array}{r}\mathrm{N}_{2} / 820^{\circ} \mathrm{C} \\
\mathrm{POCl}_{3}\end{array}$ & $\begin{array}{r}\mathrm{Fe}+\mathrm{Cu} \\
870^{\circ} \mathrm{C}\end{array}$ \\
$\mathrm{POCl}_{3}$ \\
\hline $\begin{array}{l}\text { AG Pcp. density } \\
\left(\mu \mathrm{m}^{-1}\right)\end{array}$ & 2.3 & 0.99 & 1.05 & 1.81 & 1.66 \\
$\begin{array}{l}\mathrm{PDG} \text { Pcp. density } \\
\left(\mu \mathrm{m}^{-1}\right)\end{array}$ & 1.55 & 0.95 & 0.95 & 1.61 & 1.37 \\
\hline \hline
\end{tabular}

many precipitates identified as the same particle before and after gettering. Their sizes before and after gettering are shown using arrows to guide the eye in Figure 3. From the analysis of Figure 3, it is seen that all three precipitates decrease in size dramatically, on a scale approaching an order of magnitude.

To support this automated analysis drawn from the slightly undersampled $220 \mathrm{~nm}$ pixel maps of Figure 2 (full width at half maximum, FWHM $\sim 200 \mathrm{~nm}$ ), $100 \mathrm{~nm}$ pixel maps of these three particles were taken and are shown in Figure 4. In the oversampled $(100 \mathrm{~nm}$ step size $)$ particle maps in Figure 4, the peak concentrations measured at each particle (listed in Table II) are generally higher than in the larger-area maps sampled at $220 \mathrm{~nm}$, readily expected since the precipitates are uniformly smaller than the beam FWHM. The trend from these oversampled maps is consistent with the analysis of Figure 3, which uses slightly undersampled data.

Despite the undersampling for the data of Figure 3, the trend of decreased precipitate size after phosphorus diffusion is uniformly consistent across all precipitates, even though the measurements were from two separate synchrotron runs.
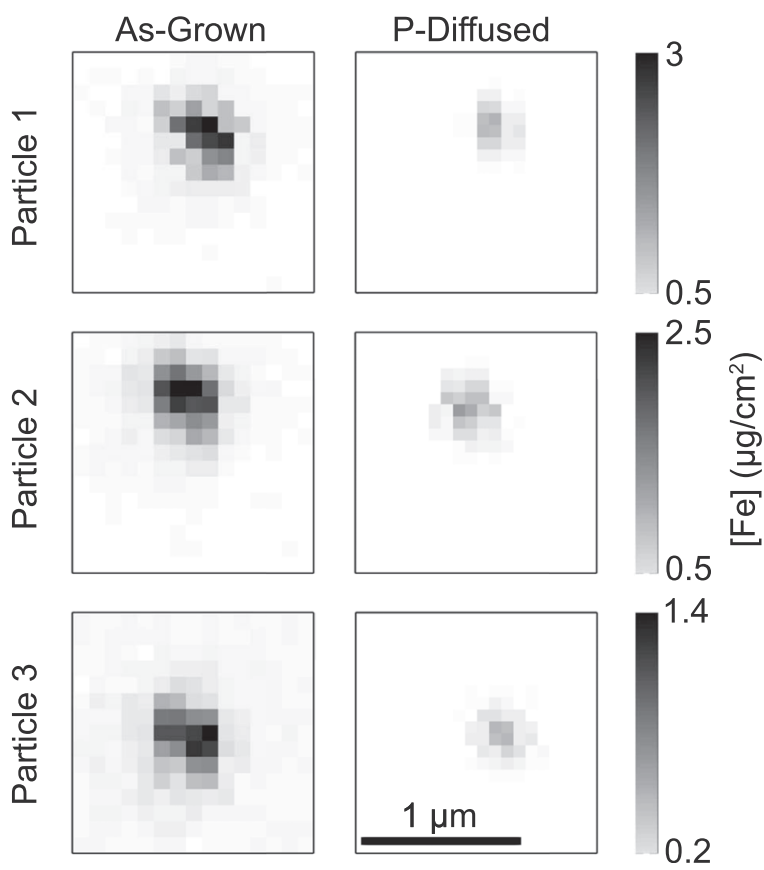

FIG. 4. High-resolution maps (100 nm pixel size) of the three particles, highlighted in Figures 2 and 3, from the $920^{\circ} \mathrm{C}$ sample before and after gettering. The number of iron atoms in each precipitate is reduced significantly. 
TABLE II. The peak concentrations at the three particles in the $920^{\circ} \mathrm{C}$ PDG sample measured using $100 \mathrm{~nm}$ and $220 \mathrm{~nm}$ step sizes are shown before and after gettering.

\begin{tabular}{lcccc}
\hline \hline & Sampling $(\mathrm{nm})$ & $\begin{array}{c}\text { Particle 1 } \\
\left(\mu \mathrm{g} / \mathrm{cm}^{2}\right)\end{array}$ & $\begin{array}{c}\text { Particle 2 } \\
\left(\mu \mathrm{g} / \mathrm{cm}^{2}\right)\end{array}$ & $\begin{array}{c}\text { Particle 3 } \\
\left(\mu \mathrm{g} / \mathrm{cm}^{2}\right)\end{array}$ \\
\hline As-grown & 220 & 2.1 & 1.7 & 1.5 \\
& 100 & 3.1 & 2.5 & 1.4 \\
P-diffused & 220 & 0.6 & 0.6 & 0.5 \\
& 100 & 1.1 & 1.2 & 0.5 \\
\hline \hline
\end{tabular}

The random repositioning of the $<50 \mathrm{~nm}$ precipitate within the $200 \mathrm{~nm}$ FWHM beam spot during the post-gettering measurement could lead to a run-to-run intensity variation of a particular precipitate of approximately a factor of 2. Yet, no case of precipitate size increase after diffusion is observed, indicating that we are most likely underestimating the overall precipitate size reduction, by up to a factor of 2 . This underestimation should be uniform in all samples due to its random nature. In short, Figure 3 should be viewed as a conservative estimate of iron reduction.

Because not all precipitates could be investigated at the highest resolution due to simple experimental time constraints, a comparison of precipitate size before and after gettering was performed using the data of Figure 3 for all precipitates that were definitively identified from Figure 2 before and after gettering. The results of this precipitate-byprecipitate size reduction analysis are shown in Figure 5 in terms of the percent reduction observed for the three Fecontaminated samples processed at different diffusion temperatures $\left(820,870\right.$, and $\left.920^{\circ} \mathrm{C}\right)$. Each point in the figure represents the reduction in size of a single precipitate after gettering. Notably, the median precipitate size reduction increases for higher temperatures, as can be seen from the boxplots to the right of the data for each sample which again show the quartiles of the distribution. While the increase in median size reduction with increasing temperature is small, and a strong reduction is seen for each temperature, the $920^{\circ} \mathrm{C}$ sample also exhibits no precipitates with less than $\sim 60 \%$ size reduction.

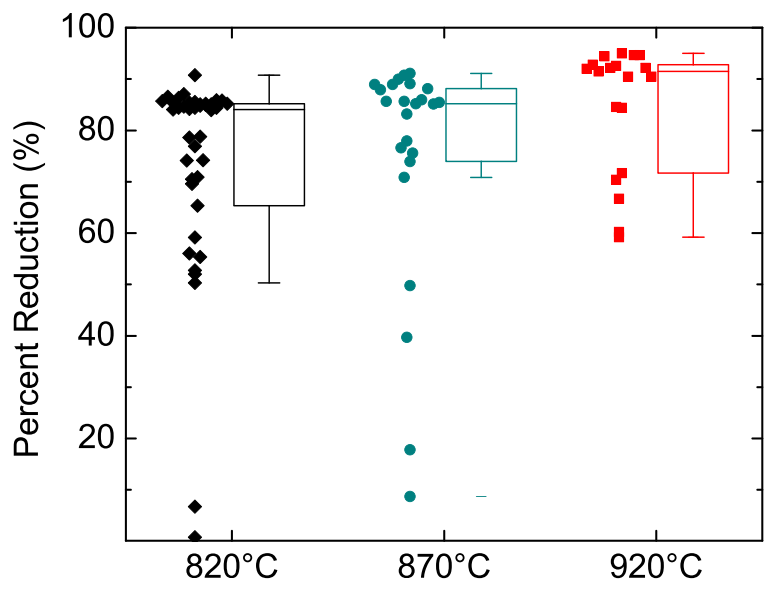

FIG. 5. The percent reduction in number of precipitated atoms of all precipitates identifiable before and after phosphorus diffusion is shown for the three different temperature processes. A trend toward higher median reduction with higher gettering temperature is seen.
Almost all of the precipitates in the fourth Fe synchrotron sample, with the $\mathrm{N}_{2}$ pre-anneal at $920^{\circ} \mathrm{C}$, were impossible to identify definitively as the same precipitate before and after gettering, mostly due to small changes in their relative positions and sizes. While preventing the same precipitate reduction analysis for the sample as in Figure 5, this difficulty in establishing congruency in the precipitates before and after high-temperature processing is in accordance with the hypothesis that a high-temperature pre-annealing step before gettering can be useful for homogenization.

To establish whether the differences in precipitate size reduction seen in Figure 5 are meaningful, pair-wise nonparametric rank-sum tests were conducted. ${ }^{30}$ The resulting $p$-values are reported in Table III. As can be seen from the table, the difference between the $920^{\circ} \mathrm{C}$ and $820^{\circ} \mathrm{C}$ distributions is highly significant, while the comparison between the $920^{\circ} \mathrm{C}$ and $870{ }^{\circ} \mathrm{C}$ samples is also significant at the 0.05 level. The difference in precipitate size reduction between the $870{ }^{\circ} \mathrm{C}$ and $820^{\circ} \mathrm{C}$ samples is significant only at the 0.065 level. Note that the $p$-values reported have no multiplecomparison adjustments, though a typical Holm-Bonferroni correction does not change the conclusions of the tests. ${ }^{31}$ Thus, we conclude that the higher-temperature gettering processes employed here reduce iron-rich precipitate sizes more than the baseline $820^{\circ} \mathrm{C}$ process.

\section{B. $\mathrm{Fe}+\mathrm{Cu}$ contaminated synchrotron sample}

In addition to the Fe-contaminated samples above, a single $\mathrm{Fe}+\mathrm{Cu}$ contaminated sample, processed using an $870^{\circ} \mathrm{C}$ phosphorus diffusion, was measured as an initial investigation into co-contamination effects. The resulting $\mu$-XRF maps of the $\mathrm{Fe}$ and $\mathrm{Cu}$ distributions are shown on the same concentration scale before and after gettering in Figure 6(a).

In the as-grown maps, one can see that all $\mathrm{Fe}$ and $\mathrm{Cu}$ precipitates are co-located and appear generally smaller than those seen in the Fe-only samples. In addition, in the $\mathrm{Cu}$ asgrown map, the position of the grain boundary is indicated by the line running across the map leading to contrast between the upper $80 \%$ of the map and the bottom $20 \%$. A small amount of the elastically scattered beam affects the $\mathrm{Cu}$ map because the $10 \mathrm{keV}$ beam is close in energy to the $\mathrm{Cu}$ $\mathrm{K}_{\alpha}$ radiation at $8047.78 \mathrm{eV}$. The contrast stems from a difference in elastic scattering between the two grains within the limited solid angle of the detector, appearing here due to a favorable positioning of the sample with respect to the detector.

TABLE III. The median reductions for the three different gettering temperatures for the Fe samples are listed. In addition, the $p$-values resulting from a rank sum test of different medians between the samples are listed. The reduction during a $920^{\circ} \mathrm{C}$ diffusion is significantly different than lower temperatures.

\begin{tabular}{lccc}
\hline \hline & $\begin{array}{c}\mathrm{Fe} 820^{\circ} \mathrm{C} \\
\mathrm{POCl}_{3}\end{array}$ & $\begin{array}{c}\mathrm{Fe} 870{ }^{\circ} \mathrm{C} \\
\mathrm{POCl}_{3}\end{array}$ & $\begin{array}{c}\mathrm{Fe} 920{ }^{\circ} \mathrm{C} \\
\mathrm{POCl}_{3}\end{array}$ \\
\hline $\begin{array}{l}\text { Median \% reduction } \\
\text { Rank sum test with } 820^{\circ} \mathrm{C} \mathrm{POCl}_{3}\end{array}$ & 84.1 & 85.3 & 91.5 \\
Rank sum test with $870{ }^{\circ} \mathrm{C} \mathrm{POCl}_{3}$ & $\ldots$ & $p=0.065$ & $p=1.3 \times 10^{-3}$ \\
\hline \hline
\end{tabular}




\section{$\underline{\mathrm{Fe}}+\mathrm{Cu}$ Contaminated Sample}

(a)
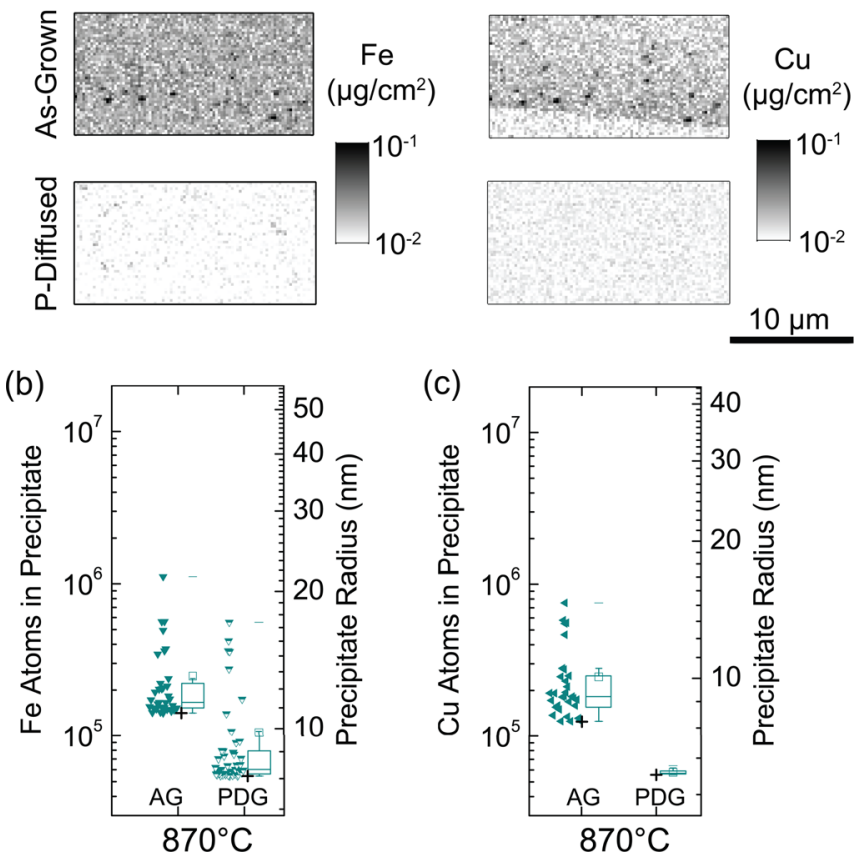

FIG. 6. $\mu$-XRF maps of $\mathrm{Fe}$ and $\mathrm{Cu}$ concentrations in the co-contaminated sample are shown in (a). The precipitate size distributions corresponding to these maps are shown for (b) $\mathrm{Fe}$ and (c) $\mathrm{Cu}$. No copper-rich precipitates are observed above the background after gettering, while small iron-rich precipitates remain. The higher background level seen for $\mathrm{Cu}$ after gettering than for $\mathrm{Fe}$ is presumably due to the proximity of the $\mathrm{Cu}$ edge to the energy of the incident beam $(10 \mathrm{keV})$ rather than high, uniform $\mathrm{Cu}$ concentration.

After phosphorus diffusion, some faint Fe-rich precipitates remain. Note that the concentration scale is shifted toward slightly smaller values than in Figure 2 in order to image these faint $\mathrm{Fe}$ precipitates. While some $\mathrm{Fe}$ remains, no $\mathrm{Cu}$ precipitates are immediately observable after gettering. Although the background level in the $\mathrm{Cu}$ XRF map after gettering is higher than for $\mathrm{Fe}$, it is expected that this background level reflects some bleed-in from the $10 \mathrm{keV}$ elastically-scattered beam rather than a uniform $\mathrm{Cu}$ concentration (which would be above $10^{16}$ atom $/ \mathrm{cm}^{3}$ and would limit the lifetime to $<1 \mu$ s (Ref. 32)).

Figure 6(b) contains the quantified Fe precipitate distribution extracted from the as-grown and gettered $\mu$-XRF maps, while Figure 6(c) shows the corresponding $\mathrm{Cu}$ precipitate distribution. The as-grown $\mathrm{Fe}$ distribution in the $\mathrm{Fe}+\mathrm{Cu}$ sample is indeed smaller with respect to those in the Fe-only samples, ranging from about $10^{5}-10^{6}$ atoms/precipitate in the $\mathrm{Fe}+\mathrm{Cu}$ sample as compared with about $2 \times 10^{5}-10^{7}$ atoms/precipitate in the Fe-only samples. Interestingly, after gettering, the background level for Fe is also particularly low in the $\mathrm{Fe}+\mathrm{Cu}$ sample, allowing for detection of smaller precipitates than in the Fe-only samples. Again, the lower background level may be a secondary indication of effective removal of total iron concentration. The automated analysis also reveals no copper-rich precipitates above the background level after gettering.

\section{Lifetime measurements}

To test the hypothesis that precipitated metal reduction is associated with improved carrier lifetime, lifetime measurements were taken on a stack of sister wafers neighboring those studied by $\mu$-XRF and processed with the same diffusion profiles.

First, we measured the as-grown lifetimes to assess the impact of the metal contamination. As-grown $\mu$-PCD lifetime measurements were performed on three samples from similar ingot heights: $\mathrm{Fe}$ contaminated, $\mathrm{Fe}+\mathrm{Cu}$ contaminated, and also just $\mathrm{Cu}$ contaminated (also contaminated in the melt by 20 ppma $\mathrm{Cu}$ for comparison). The as-grown lifetime maps for these three different contaminations are shown in Figure 7. Comparing the $\mathrm{Fe}$ and $\mathrm{Fe}+\mathrm{Cu}$ contaminated wafers to the $\mathrm{Cu}$ contaminated wafer, the lifetime measurements reveal that the as-grown lifetimes in these wafers are dominated by iron, since the as-grown lifetimes in the $\mathrm{Cu}$ only wafer are much higher. Lifetimes in the iron-limited wafers are below $\sim 3 \mu$ s, which is also typical of material originating from the red zone of ingots. The remainder of the lifetime measurements focuses on how processing affects these iron-limited wafers.

The spatially resolved lifetime maps of the sister samples after phosphorus diffusion are shown in Figure 8 for (a)-(d) the Fe-contaminated ingot and (e)-(h) the $\mathrm{Fe}+\mathrm{Cu}$ contaminated ingot, while the area-averaged results are summarized in Table IV. Both the arithmetic average and the harmonic average are included, as the harmonic average is a better
Fe contaminated
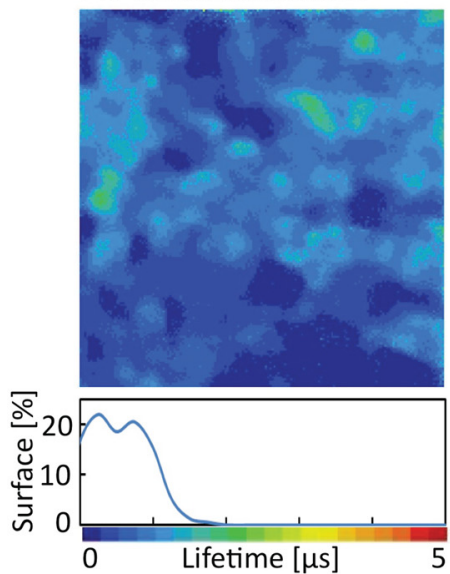

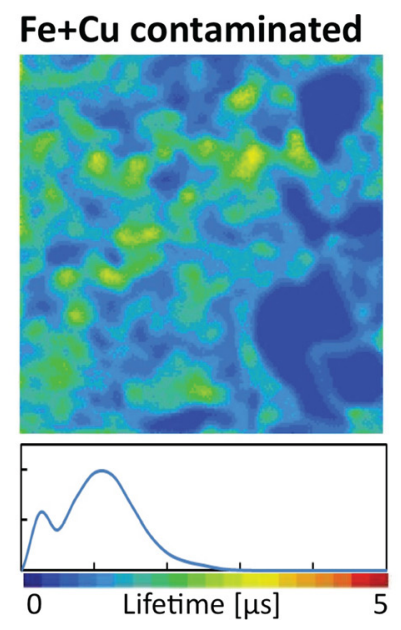

\section{Cu contaminated}

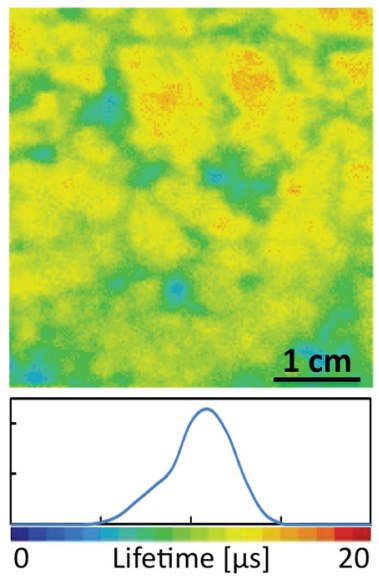

FIG. 7. As-grown $\mu$-PCD lifetime measurement of three typical wafers from the tops of the $\mathrm{Fe}, \mathrm{Fe}+\mathrm{Cu}$, and $\mathrm{Cu}$ contaminated ingots. Note the different scale bar for the $\mathrm{Cu}$ contaminated wafer. The low lifetimes in the $\mathrm{Fe}$ and $\mathrm{Fe}+\mathrm{Cu}$ wafers can be attributed to the impact of iron contamination. 


\section{Fe contaminated ingot:}

(a) $820^{\circ} \mathrm{CPOCl}_{3}$

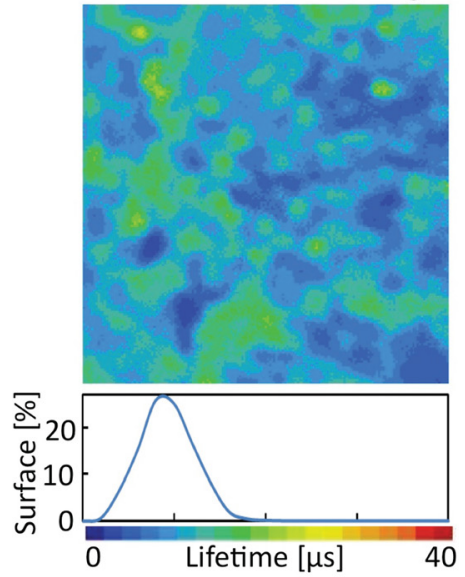

(b) $870^{\circ} \mathrm{C} \mathrm{POCl}_{3}$
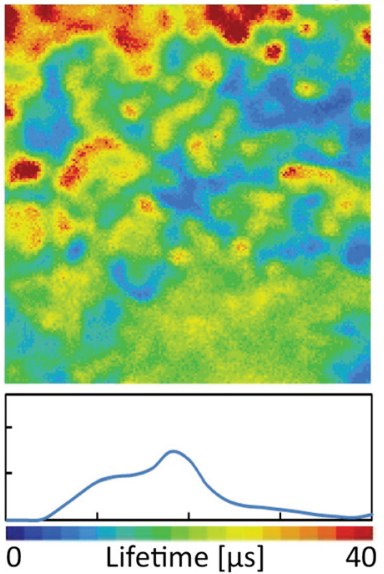

(c) $920^{\circ} \mathrm{C} \mathrm{POCl}$
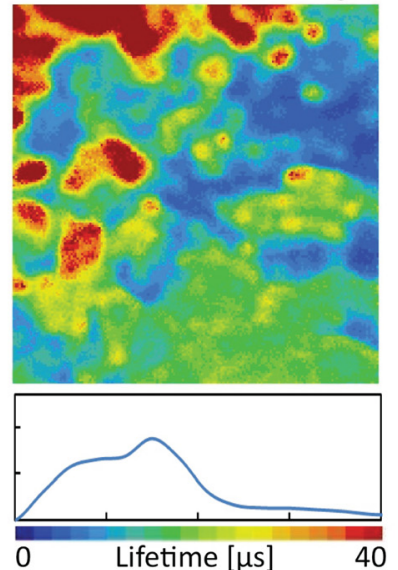

(d) $920^{\circ} \mathrm{C} / 820^{\circ} \mathrm{C} \mathrm{POCl}_{3}$

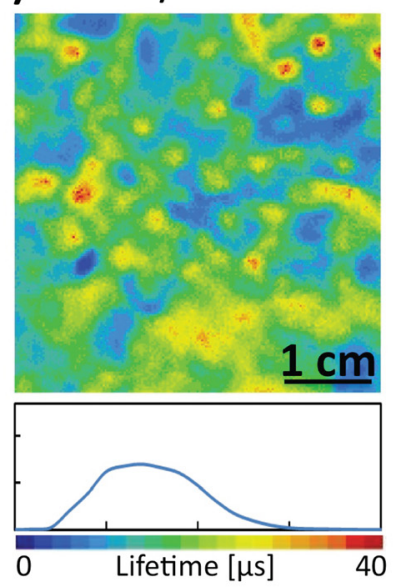

$\mathrm{Fe}+\mathrm{Cu}$ contaminated ingot:

(e) $820^{\circ} \mathrm{C} \mathrm{POCl}_{3}$
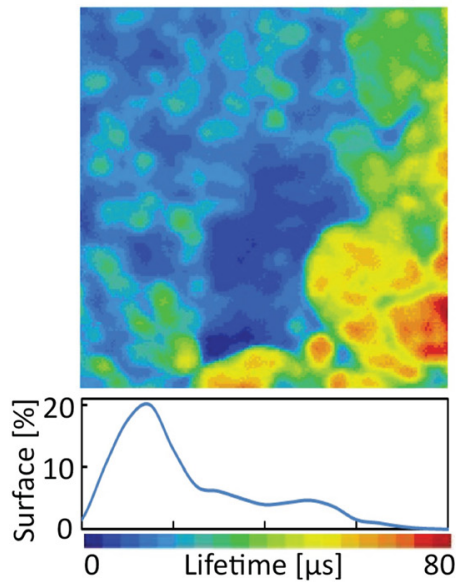

(f) $870^{\circ} \mathrm{C} \mathrm{POCl}_{3}$

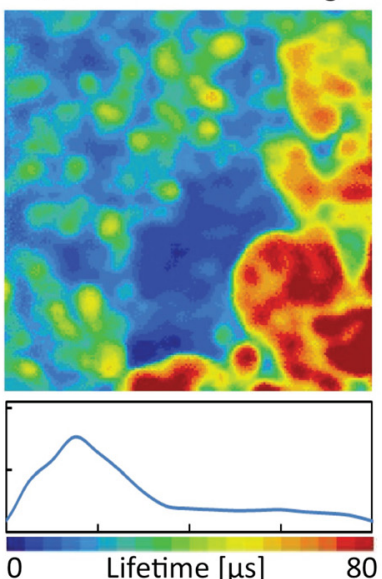

(g) $920^{\circ} \mathrm{C} \mathrm{POCl}$
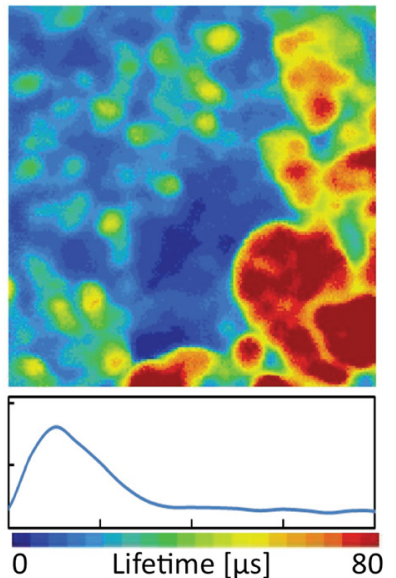

(h) $920^{\circ} \mathrm{C} / 820^{\circ} \mathrm{CPOCl}_{3}$

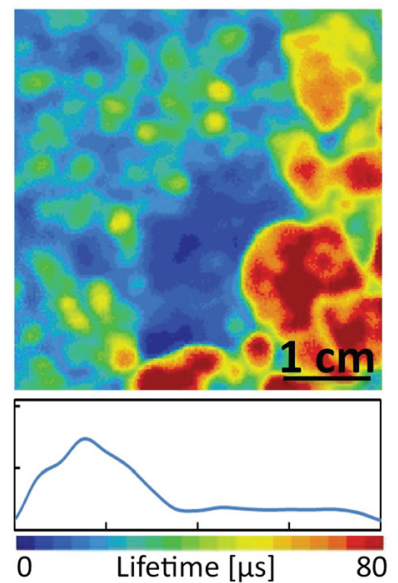

FIG. 8. Post-diffusion $\mu$-PCD lifetime maps with $250 \mu \mathrm{m}$ resolution are shown. Note the different scale bar between (a)-(d) the Fe contaminated samples and (e)-(h) the $\mathrm{Fe}+\mathrm{Cu}$ contaminated samples. The lifetime improves significantly in many regions of the sister wafers when moving to higher temperature diffusions. A pre-diffusion step at $920^{\circ} \mathrm{C}$ followed by an $820^{\circ} \mathrm{C}$ diffusion is seen in (h) to achieve similar lifetimes as the $920^{\circ} \mathrm{C}$ diffusion (g) for the Fe $+\mathrm{Cu}$ contaminated samples. For the Fe-only samples, the highest lifetimes in the pre-annealed sample (d) are lower with respect to the higher-temperature P-diffusions (b) and (c), though homogeneity is improved.

assessment of future solar cell quality than the simple arithmetic average. ${ }^{33}$

Focusing first on the Fe-contaminated samples, lifetimes improve dramatically across the entire sample moving from (a) the $820^{\circ} \mathrm{C}$ diffusion to (b) the $870{ }^{\circ} \mathrm{C}$ diffusion. Moving to even higher temperatures, to $920^{\circ} \mathrm{C}$ in (c), yields lifetime improvement over a large area of the sample, mainly in the higher lifetime areas. However, in the upper right region of

TABLE IV. Averaged $\mu$-PCD lifetime measurements on sister samples, processed by different phosphorus diffusions. The arithmetic and harmonic average lifetimes are calculated to weight the heterogeneity of the distribution. Also included are the sheet resistance measurements made on the Cz samples included in each of the diffusions.

\begin{tabular}{|c|c|c|c|c|c|}
\hline \multirow[b]{2}{*}{ Ingot } & \multirow[b]{2}{*}{ Lifetime $(\mu \mathrm{s})$} & \multicolumn{4}{|c|}{ P-diffusion process } \\
\hline & & $820^{\circ} \mathrm{C}$ & $870^{\circ} \mathrm{C}$ & $920^{\circ} \mathrm{C}$ & $920^{\circ} \mathrm{C} / 820^{\circ} \mathrm{C}$ \\
\hline \multirow[t]{3}{*}{$\mathrm{Fe}$} & As-grown & \multicolumn{4}{|c|}{$0.68 \pm 0.4$} \\
\hline & Final arithmetic & $10.3 \pm 2.9$ & $18.9 \pm 7.2$ & $17.9 \pm 10.5$ & $16.0 \pm 5.3$ \\
\hline & Final harmonic & 9.4 & 16.3 & 13.1 & 14.2 \\
\hline \multirow[t]{3}{*}{$\mathrm{Fe}+\mathrm{Cu}$} & As-grown & \multicolumn{4}{|c|}{$1.2 \pm 0.5$} \\
\hline & Final arithmetic & $25.5 \pm 15.8$ & $32.7 \pm 22.0$ & $32.2 \pm 25.3$ & $33.1 \pm 22.5$ \\
\hline & Final harmonic & 17.1 & 19.6 & 16.6 & 19.6 \\
\hline $\mathrm{Cz}$ & Sheet resistance $(\Omega /$ sq. $)$ & $62.6 \pm 1.6$ & $23.2 \pm 0.6$ & $10.6 \pm 0.2$ & $67.6 \pm 1.7$ \\
\hline
\end{tabular}


the sample, the lifetime is seen to be lower in (c) than in (b). The map of lifetime (d) after the $920^{\circ} \mathrm{C}$ pre-anneal followed by an $820^{\circ} \mathrm{C}$ P-diffusion yields markedly different results from any of the standard diffusions. In (d), the lifetime distribution is narrower, supporting the idea of the preanneal as a homogenization step, though the highest lifetimes of the higher-temperature diffusions of (b) and (c) are not achieved. Still, the lifetime distribution is shifted to significantly higher values with respect to (a) the $820^{\circ} \mathrm{C}$ standard $\mathrm{P}$-diffusion, even though the $\mathrm{POCl}_{3}$ process occurs at the same temperature.

In the $\mathrm{Fe}+\mathrm{Cu}$ samples, a similar pattern emerges comparing the lifetime results after processing. The lifetime steadily improves in the right hand portion of the sample by increasing the gettering temperature successively from (e) $820^{\circ} \mathrm{C}$ to (f) $870^{\circ} \mathrm{C}$ to $(\mathrm{g}) 920^{\circ} \mathrm{C}$. The improvement of $(\mathrm{g})$ $920^{\circ} \mathrm{C}$ gettering over (f) $870^{\circ} \mathrm{C}$ gettering in this region appears less than that by moving to $870^{\circ} \mathrm{C}$ over (e) $820^{\circ} \mathrm{C}$. The center of the samples does not improve dramatically in any process. In contrast to the Fe-only sample, the lifetime spatial distribution after the $920^{\circ} \mathrm{C}$ pre-anneal in the $\mathrm{Fe}+\mathrm{Cu}$ sample (h) compares quite closely with the spatial distribution in the other sisters (e)-(g). Once again, though, the lifetimes are significantly higher in $(\mathrm{h})$ the pre-annealed sample with respect to (e) the $820^{\circ} \mathrm{C}$ standard diffusion despite the same P-diffusion temperature.

The lowest lifetime areas after gettering are consistent across the Fe-only sisters (a)-(d) and, separately, across the $\mathrm{Fe}+\mathrm{Cu}$ sisters (e)-(h), indicating that in these regions certain defects persist despite the different gettering processes.

\section{DISCUSSION}

\section{A. Iron-contaminated material}

The principal hypothesis of this work is that higher processing temperatures offer a path to improve material quality in iron-limited materials through increased extraction of precipitated metals during the phosphorus diffusion gettering process. By accelerating the external gettering process, highertemperature processing should improve bulk lifetime and allow for acceptable device efficiency even from degraded as-grown materials. Attacking total metal concentrations can also be vital to device performance outside of the impact on lifetime. Precipitates have shown to lead to early breakdown and shunting, which must be avoided for long module lifetimes. ${ }^{34,35}$

The improved gettering of precipitated metals with increasing processing temperature seen herein with synchrotron-based $\mu$-XRF measurements supports the stated hypothesis. Using a set of sister samples subjected to increasing processing temperatures and measured before and after gettering, we confirm on the microscopic scale that increasing temperature results in enhanced iron-rich precipitate size reduction (Figures 2-5). The largest median precipitate size reduction of over $90 \%$ occurs in the sample gettered at $920^{\circ} \mathrm{C}$. In correspondence with this improved precipitate size reduction at higher temperatures, lifetime increases in most areas of the metal-contaminated samples (Figure 8), with nearly $80 \%$ higher average arithmetic lifetimes seen in both the $870^{\circ} \mathrm{C}$ and $920^{\circ} \mathrm{C} \mathrm{Fe}$-contaminated samples, though the final harmonic lifetime is highest after $870^{\circ} \mathrm{C}$ gettering.

The largest relative lifetime improvements by moving to higher temperatures are seen in Fe-contaminated samples. In fact, the absolute improvement in lifetime between the higher temperature gettering steps and the baseline $820^{\circ} \mathrm{C}$ gettering process $\left(8.6\right.$ and $7.6 \mu \mathrm{s}$ for the $920^{\circ} \mathrm{C}$ and $870{ }^{\circ} \mathrm{C}$ P-diffusions, respectively) is almost as large as the difference between the $820^{\circ} \mathrm{C}$ gettered lifetime and the as-grown lifetime $(9.6 \mu \mathrm{s})$.

In general, when cooling from higher-temperature anneals, care must be taken to avoid "poisoning" the wafer with iron point defects. Fast cools have been shown to "lock in" high concentrations of iron point defects, sharply reducing lifetime. In industrial production, it is common practice to pull wafers from the furnace at high temperatures, effectively quenching in high-temperature impurity distributions. A modified cooling treatment may be necessary to adapt higher-temperature anneals in practice, and to avoid low lifetimes reported in previous studies. ${ }^{20,21}$

In the above experiments, process time has been held constant to isolate the effect of temperature. Other possible constraints, such as the sheet resistance of the emitter, have been relaxed, although all diffusions here achieved a surface phosphorus concentration above the electrically active limit of $\sim 3 \times 10^{20}$ atoms $/ \mathrm{cm}^{3}$, 36 which should mean that both segregation and relaxation gettering mechanisms are active in all samples. ${ }^{37}$

In general, a lower sheet resistance does not necessarily imply better gettering. This is in part because the emitter sheet resistance is dominated by the depth of the high-concentration plateau in the kink-and-tail profile. ${ }^{38}$ Iron profiles are generally seen to be confined to a region very near the surface that is much narrower than the high-concentration plateau even for extended gettering steps that result in lower sheet resistance (see, e.g., Ref. 39). Rather than strictly depending on the emitter sheet resistance, gettering efficacy depends strongly on the exact nature of the time-temperature profile.

Extending gettering time and increasing gettering temperature are two ways to achieve a longer diffusion length of iron during processing, but an increase in temperature rather than time is more powerful because of the Arrhenius relationship of iron diffusivity. Iron solubility also has an Arrhenius form, and so precipitate dissolution should be markedly higher with higher temperatures. Demonstrating the impact of the kinetics, we have shown that for approximately the same process throughput we can reduce the precipitated iron concentration after higher-temperature gettering, and we correlate this reduction with improved lifetime.

A heavier phosphorus diffusion is produced, but the etch back of a strongly diffused emitter has already been achieved for selective-emitter designs. ${ }^{40-42}$ Such processes could potentially be applied to produce uniformly better blue response for an industrial emitter after a heavy diffusion aimed at gettering precipitated iron.

\section{B. Co-contamination effects $(\mathrm{Fe}+\mathrm{Cu})$}

In the $\mathrm{Fe}+\mathrm{Cu}$ co-contaminated synchrotron sample, the as-grown distribution of precipitates is shifted toward 
smaller sizes. Previously, mixed-metal silicides have been observed, ${ }^{43,44}$ but limited solubility of one element in the others' silicide often results in two co-located precipitates. ${ }^{4}$ Such precipitates are predominantly a single metal, justifying our approximation of independent spherical precipitates of each metal type for analyzing size distributions in the $\mathrm{Fe}+\mathrm{Cu} \mu$-XRF map. Still, interactions between the precipitating species appear important in explaining the smaller measured as-grown distribution. Copper has a large energy barrier to nucleation in silicon, ${ }^{45}$ but with co-precipitation a reduction in this barrier may explain the more widespread precipitation seen here in the $\mathrm{Cu}+\mathrm{Fe}$ sample relative to the Fe only samples.

The change in the iron distribution after $870{ }^{\circ} \mathrm{C}$ PDG is also more significant in the $\mathrm{Fe}+\mathrm{Cu}$ sample than in the $\mathrm{Fe}$ only contaminated sample, as there is no overlap in the distribution parameters before and after gettering in the $\mathrm{Fe}+\mathrm{Cu}$ sample (Figure 6). Two effects may explain this more significant extraction of precipitated metals. First, for a given gettering temperature, smaller precipitate sizes should result in improved gettering due to faster kinetics. ${ }^{46}$ Second, reversing the apparently enhanced co-precipitation process, during gettering as the solubility rises with temperature dissolving $\mathrm{Cu}_{3} \mathrm{Si}$ precipitates may create a high local concentration of vacancies, speeding $\mathrm{FeSi}_{2}$ precipitate dissolution.

Ultimately, higher post-gettered lifetimes are measured in the $\mathrm{Fe}+\mathrm{Cu}$ samples compared to the $\mathrm{Fe}$ contaminated samples irrespective of the process, despite higher initial total metal concentrations in the $\mathrm{Fe}+\mathrm{Cu}$ wafers. However, the relative lifetime increase resulting from high-temperature annealing appears less impressive in the $\mathrm{Fe}+\mathrm{Cu}$ materials tested, which have smaller (or undetectable) iron-rich precipitates. In such co-contaminated material, higher-temperature annealing appears to have less of a beneficial effect on lifetime improvement, since lower-temperature $\mathrm{POCl}_{3}$ appears to satisfactorily remediate precipitated iron.

\section{Homogenization pre-annealing}

As a possible alternative to higher P-diffusion temperatures in metal-contaminated samples that maintains a sheet resistance appropriate for devices, a pre-anneal in nitrogen at temperatures higher than a subsequent P-diffusion is seen here to improve lifetime over a baseline process, confirming previous results. ${ }^{18,24}$ Little internal or external gettering is observed for high-iron wafers processed solely in an $\mathrm{N}_{2}$ environment, ${ }^{47}$ as anneals in $\mathrm{N}_{2}$ should have no strong driving force for a unidirectional flux to the surface. Instead, largely isotropic dissolution/diffusion should occur at process temperature, resulting potentially in homogenization. Along these lines, in the pre-annealed sample here, the position of the precipitates after the pre-annealing and diffusion is similar to but not exactly the same as the as-grown distribution. A similar pattern of dissolution and reprecipitation at almost identical, but slightly differing sites was seen by in-situ $\mu$-XRF measurements during heating and cooling of a Ni-contaminated $\mathrm{Cz}$ sample with precipitation occurring at bulk microdefects. ${ }^{48}$ In addition to the slightly differing precipitate positions in the pre-annealed sample, from our
$\mu$-XRF measurements, we conclude that it appears there is a significant decrease in total metal concentration during the two-step $920^{\circ} \mathrm{C} \mathrm{N}_{2} / 820^{\circ} \mathrm{C}$ P-diffusion process. The changes in the precipitated iron distribution after two-step treatment appears closest to the corresponding results from the $870^{\circ} \mathrm{C}$ P-diffusion and improved over the baseline $820^{\circ} \mathrm{C}$ P-diffusion.

The resulting arithmetic average lifetime in the Fecontaminated sample after the two-step treatment is lower than the average lifetime for the $870^{\circ} \mathrm{C}$ and $920^{\circ} \mathrm{C}$ processes, largely because the lifetime distribution does not have the same high-lifetime tail as the $870^{\circ} \mathrm{C}$ and $920^{\circ} \mathrm{C}$ samples. Because of improved homogeneity over the $920^{\circ} \mathrm{C}$ sample, however, when considering the harmonic average lifetime, the two-step process is second only to the $870{ }^{\circ} \mathrm{C} \mathrm{P}$-diffusion.

\section{v. CONCLUSION}

In this contribution, synchrotron-based $\mu$-XRF provides a microscopic assessment of the effect of gettering temperature on precipitate size reduction. We analyze the precipitate size distribution in the $2 \mathrm{D}$ spatial maps to quantify process comparisons statistically. By rigorously measuring the same precipitates before and after high temperature processing, we confirm that higher-temperature diffusions successfully extract a greater fraction of the precipitated metal content. Lifetime mappings on a macroscopic scale of neighboring samples relate this reduction in precipitated metal content to significant improved lifetime in iron-dominated samples.

When considering the design of a gettering process, it is critical to assess what defect limits lifetime in that material. If the limiting defect is iron, precipitate dissolution and bulk iron removal increases markedly moving to higher temperatures, demonstrated directly using $\mu$-XRF measurements herein. Notably, when moving to higher processing temperatures, the interstitial iron concentration may be relatively higher at the start of the cooldown from diffusion temperature due to the higher solubility. This high interstitial concentration requires further defect engineering during cooling and subsequent metallization, such as slow-cooling or lowtemperature annealing. Nonetheless, higher processing temperatures may be one of the few ways to circumvent higher contamination levels using process control to achieve dramatically improved lifetimes that enable quality cell efficiencies.

Homogenization pre-annealing may also prove a useful industrial process near-term since little is required for implementation, though benefits may be limited in comparison with high-temperature P-diffusion. A combination of preannealing and moderately elevated phosphorus diffusion may prove most beneficial. A large parameter space remains open here for exploration of such combined process optimization.

\section{ACKNOWLEDGMENTS}

The authors would like to thank Lisa Mahlstaedt for assistance with the diffusions, Jörg Bernhard for assistance with EBIC and EBSD pre-characterizations of the samples, and Bonna K. Newman for assistance during as-grown 
synchrotron measurements. The U.S. portion of this work was supported in part by the U. S. Department of Energy, contract number DE-FG36-09GO19001, and by the National Science Foundation (NSF) and the Department of Energy (DOE) under NSF CA No. EEC-1041895. The German portion of this work was supported by the German Department of Environment and Nuclear Safety in the frame of the SolarFocus project $(032765 \mathrm{H} 9)$ as well as the Ministry of Science, Research and the Arts of Baden-Württemberg, Germany. D.P.F. acknowledges the support of the NSF Graduate Research Fellowship and the Martin Family Society of Fellows at MIT. Use of the Advanced Photon Source at Argonne National Laboratory was supported by the U.S. Department of Energy, Office of Science, Office of Basic Energy Sciences, under Contract No. DE-AC02$06 \mathrm{CH} 11357$.

${ }^{1}$ A. Goodrich, T. James, and M. Woodhouse, "Residential, Commercial, and Utility-Scale Photovoltaic (PV) System Prices in the United States: Current Drivers and Cost-Reduction Opportunities," Tech. Rep. NREL/ TP-6A20-53347 (NREL, 2012).

${ }^{2}$ D. M. Powell, M. T. Winkler, H. J. Choi, C. B. Simmons, D. Berney Needleman, and T. Buonassisi, Energy Env. Sci. 5, 5874 (2012).

${ }^{3}$ T. Trupke, K. R. McIntosh, J. W. Weber, W. McMillan, L. Ryves, J. Haunschild, C. Shen, and H. Kampwerth, in 22nd Workshop on Crystalline Silicon Solar Cells and Modules (Vail, CO, July 2012).

${ }^{4}$ S. Riepe, I. E. Reis, W. Kwapil, M. A. Falkenberg, J. Schön, H. Behnken, J. Bauer, D. Kreßner-Kiel, W. Seifert, and W. Koch, Phys. Status Solidi C 8, 733 (2011)

${ }^{5}$ G. Coletti, R. Kvande, V. D. Mihailetchi, L. J. Geerligs, L. Arnberg, and E. J. Øvrelid, J. Appl. Phys. 104, 104913 (2008).

${ }^{6}$ J. R. Davis, Jr., A. Rohatgi, R. H. Hopkins, P. D. Blais, P. Rai-Choudhury, J. R. McCormick, and H. C. Mollenkopf, IEEE Trans. Electron Devices 27, 677 (1980).

${ }^{7}$ T. U. Naerland, L. Arnberg, and A. Holt, Prog. Photovolt. Res. Appl. 17, 289 (2009).

${ }^{8}$ M. Rinio, A. Yodyunyong, S. Keipert-Colberg, Y. P. B. Mouafi, D. Borchert, and A. Montesdeoca-Santana, Prog. Photovolt. Res. Appl. 19, 165 (2011).

${ }^{9}$ J. Härkönen, V.-P. Lempinen, T. Juvonen, and J. Kylmäluoma, Solar Energy Mater. Solar Cells 73, 125 (2002).

${ }^{10}$ M. D. Pickett and T. Buonassisi, Appl. Phys. Lett. 92, 122103 (2008).

${ }^{11}$ P. Manshanden and L. J. Geerligs, Solar Energy Mater. Solar Cells 90, 998 (2006)

${ }^{12}$ R. Krain, S. Herlufsen, and J. Schmidt, Appl. Phys. Lett. 93, 152108 (2008).

${ }^{13}$ D. P. Fenning, J. Hofstetter, M. I. Bertoni, S. Hudelson, M. Rinio, J. F. Lelièvre, B. Lai, C. del Cañizo, and T. Buonassisi, Appl. Phys. Lett. 98, 162103 (2011).

${ }^{14}$ J. Schön, A. Haarahiltunen, H. Savin, D. P. Fenning, T. Buonassisi, W. Warta, and M. C. Schubert, IEEE J. Photovolt. 3, 131 (2012).

${ }^{15}$ J. Hofstetter, J.-F. Lelièvre, D. P. Fenning, M. I. Bertoni, T. Buonassisi, and C. del Cañizo, Solid State Phenom. 178-179, 158 (2011).

${ }^{16}$ J. Tan, D. Macdonald, N. Bennett, D. Kong, A. Cuevas, and I. Romijn, Appl. Phys. Lett. 91, 043505 (2007).

${ }^{17}$ J.-F. Lelièvre, J. Hofstetter, A. Peral, I. Hoces, F. Recart, and C. del Cañizo, Energy Procedia 8, 257 (2011).

${ }^{18}$ B. Michl, J. Schön, F. Schindler, W. Warta, and M. C. Schubert, in Proceedings of the 27th EUPVSEC (Franfurt, Germany, 2012), pp. 709-713.

${ }^{19}$ P. S. Plekhanov, R. Gafiteanu, U. M. Gösele, and T. Y. Tan, J. Appl. Phys. 86, 2453 (1999).
${ }^{20}$ S. Peters, J. Y. Lee, C. Ballif, D. Borchert, S. W. Glunz, W. Warta, and G. Willeke, in Proceedings of the 29th IEEE PVSC (IEEE, New Orleans, LA, 2002), pp. 214-217.

${ }^{21}$ C. Ballif, S. Peters, D. Borchert, C. Hässler, J. Isenberg, R. Schindler, W. Warta, and G. Willeke, in Proceedings of the 17th EU PVSEC (Munich, Germany, 2001), p. 1818.

${ }^{22}$ D. Macdonald and A. Cuevas, in Proceedings of the 16th EU PVSEC (Glasgow, Scotland, 2000), pp. 1707-1710.

${ }^{23}$ V. Osinniy, A. Nylandsted Larsen, E. Hvidsten Dahl, E. Enebakk, A.-K. Søiland, R. Tronstad, and Y. Safir, Solar Energy Mater. Solar Cells 101, 123 (2012).

${ }^{24}$ J. Schön, H. Habenicht, M. C. Schubert, and W. Warta, J. Appl. Phys. 109, 063717 (2011).

${ }^{25}$ D. Macdonald, S. P. Phang, F. E. Rougieux, S. Y. Lim, D. Paterson, D. L. Howard, M. D. de Jonge, and C. G. Ryan, Semicond. Sci. Technol. 27, 125016 (2012).

${ }^{26}$ Z. Cai, B. Lai, W. Yun, I. McNulty, A. Khounsary, J. Maser, P. Ilinski, D. Legnini, E. Trakhtenberg, S. Xu, B. Tieman, G. Wiemerslage, and E. Gluskin, in AIP CP 521, Synchrotron Radiation Instrumentation: Eleventh US National Conference (American Institute of Physics, Stanford, CA, 1999), pp. 31-34.

${ }^{27}$ A. Zuschlag and G. Hahn, in Proceedings of the 26th EU PVSEC (Hamburg, Germany, 2011), pp. 1547-1549.

${ }^{28}$ K. L. Pollock, J. Junge, and G. Hahn, IEEE J. Photovolt. 2, 1 (2012).

${ }^{29}$ D. P. Fenning, J. Hofstetter, M. I. Bertoni, G. Coletti, B. Lai, C. del Cañizo, and T. Buonassisi, J. Appl. Phys. 113, 044251 (2013).

${ }^{30}$ E. L. Lehmann and J. M. D'Abrera, Nonparametrics: Statistical Methods Based on Ranks (Springer, New York, 2006).

${ }^{31}$ S. Holm, Scand. J. Stat. 6, 65 (1979); available at http://www.jstor.org/stable/ 4615733 .

${ }^{32}$ A. A. Istratov, T. Buonassisi, M. D. Pickett, M. Heuer, and E. R. Weber, Mater. Sci. Eng. B 134, 282 (2006).

${ }^{33}$ J. Isenberg, J. Dicker, and W. Warta, J. Appl. Phys. 94, 4122 (2003).

${ }^{34}$ W. Kwapil, P. Gundel, M. C. Schubert, F. D. Heinz, W. Warta, E. R. Weber, A. Goetzberger, and G. Martinez-Criado, Appl. Phys. Lett. 95, 232113 (2009).

${ }^{35}$ T. Buonassisi, O. F. Vyvenko, A. A. Istratov, E. R. Weber, G. Hahn, D. Sontag, J. P. Rakotoniaina, O. Breitenstein, J. Isenberg, and R. Schindler, J. Appl. Phys. 95, 1556 (2004).

${ }^{36}$ A. Bentzen, A. Holt, J. S. Christensen, and B. G. Svensson, J. Appl. Phys. 99, 064502 (2006).

${ }^{37}$ S. M. Myers, M. Seibt, and W. Schröter, J. Appl. Phys. 88, 3795 (2000).

${ }^{38}$ A. Bentzen, G. Schubert, J. S. Christensen, B. G. Svensson, and A. Holt, Prog. Photovolt. Res. Appl. 15, 281 (2006).

${ }^{39}$ H. Talvitie, V. Vähänissi, A. Haarahiltunen, M. Yli-Koski, and H. Savin, J. Appl. Phys. 109, 093505 (2011).

${ }^{40}$ H. Haverkamp, A. Dastgheib-Shirazi, B. Raabe, F. Book, and G. Hahn, "Minimizing the electrical losses on the front side: development of a selective emitter process from a single diffusion," in Proceedings of the 33rd IEEE PVSC (IEEE, San Diego, CA, 2008), pp. 430-433.

${ }^{41}$ D. Rudolph, K. Peter, A. Meijer, O. Doll, and I. Köhler, in Proceedings of the 26th EU PVSEC (Hamburg, Germany, 2011), pp. 1349-1352.

${ }^{42}$ A.-K. Volk, U. Jaeger, J. Rentsch, and R. Preu, in Proceedings of the 26th EU PVSEC (Hamburg, Germany, 2011), pp. 884-889.

${ }^{43}$ M. Heuer, T. Buonassisi, M. A. Marcus, A. A. Istratov, M. D. Pickett, T. Shibata, and E. R. Weber, Phys. Rev. B 73, 5 (2006).

${ }^{44}$ T. Buonassisi, M. Heuer, A. A. Istratov, M. D. Pickett, M. A. Marcus, B. Lai, Z. Cai, S. M. Heald, and E. R. Weber, Acta Mater. 55, 6119 (2007)

${ }^{45}$ H.-W. Guo and S. T. Dunham, Appl. Phys. Lett. 89, 182106 (2006).

${ }^{46}$ J. Hofstetter, D. P. Fenning, J.-F. Lelièvre, C. del Cañizo, and T. Buonassisi, Phys. Status Solidi A 209, 1861 (2012).

${ }^{47}$ J. Hofstetter, J. F. Lelièvre, C. del Cañizo, and A. Luque, Solid State Phenom. 156-158, 387 (2010).

${ }^{48}$ D. P. Fenning, M. I. Bertoni, and T. Buonassisi, in 5th International Workshop of Crystalline Silicon Solar Cells (Boston, MA, 2011). 